\title{
Armazenamento de sementes de carolina em diferentes temperaturas e embalagens
}

\author{
Storage of carolina seeds in different temperature and packing
}

\author{
Camila de Oliveira ${ }^{\mathrm{I}}$ Breno Marques da Silva e Silva ${ }^{\mathrm{II}}$ Rubens Sader ${ }^{\mathrm{III}}$ \\ Fabiola Vitti Môro"II
}

\section{RESUMO}

\begin{abstract}
O objetivo do presente trabalho foi determinar a embalagem e a temperatura adequadas para o armazenamento de sementes de carolina. As sementes foram armazenadas em sacos de papel e de plástico, mantidas em $0 \pm 2 ; 10 \pm 2 ; 20 \pm 2^{\circ} \mathrm{C}$ e $60 \pm 5 \%$ de umidade relativa do ar (UR) e em temperatura ambiente $\left(23,4 \pm 3,3^{\circ} \mathrm{C}\right)$ e $68,7 \pm 9 \% U R$. $O$ teor de água, a germinação e o vigor foram determinados trimestralmente. Durante o armazenamento, o teor de água das sementes foi de aproximadamente 8,9\%. A embalagem saco de plástico e a temperatura de $0^{\circ} \mathrm{C}$ são adequadas para o armazenamento das sementes de carolina.
\end{abstract}

Palavras-chave: Adenanthera pavonina L., germinação, vigor, conservação de sementes, Fabaceae.

\section{ABSTRACT}

The objective of the present research was to determine the more adequated packing and temperature for storage of "carolina" seeds. The seeds were stored in paper and plastic packings and kept in $0 \pm 2 ; 10 \pm 2 ; 20 \pm 2^{\circ} \mathrm{C}$ and $60 \pm 5 \%$ air relative humidity $(A R H)$ and in ambient temperature $\left(23,4 \pm 3,3^{\circ} \mathrm{C}\right)$ and $68,7 \pm 9 \%$ ARH. Quarterly, the water seed content, germinative test and seed vigour were avaluated. During storage, the seed water content was approximately $8.9 \%$. The plastic packing (plastic bag) and tempertature of $0^{\circ} \mathrm{C}$ are adequated for storage of "carolina" seeds.

Key words: Adenanthera pavonina L., germination, vigor, conservation of seed, Fabaceae.

\section{INTRODUÇÃO}

Adenanthera pavonina L., pertencente à família Fabaceae, conhecida popularmente por carolina, olho-de-dragão ou tento é uma árvore nativa da Índia e Malásia que foi introduzida no Brasil e nas Américas para a composição da arborização urbana e rural (LORENZI et al., 2003; ROCAS, 2003). Para a produção de mudas de carolina, foram realizadas pesquisas em tecnologia de sementes e análise do crescimento de mudas, no entanto, os estudos sobre o armazenamento de suas sementes são escassos e, especialmente, com relação a influência das embalagens e temperaturas.

A deterioração é um processo natural e inevitável de desestruturação física e da perda de capacidade fisiológica, mas passível de controle, sendo essa a essência do armazenamento, que está entre as estratégias de conservação ex situ (NODARI et al., 1998; CARVALHO et al., 2006). De acordo com CARVALHO \& NAKAGAWA (2000), BONNER (2001) e HONG \& ELLIS (2003), a longevidade das sementes armazenadas é influenciada, principalmente, pela sua qualidade inicial, pelo teor de água, tempo decorrido entre a colheita e o armazenamento, tratamentos fitossanitários e térmicos aplicados, tipo de embalagem, temperatura e umidade relativa do ambiente de armazenamento.

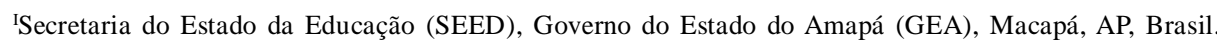

"Instituto de Pesquisas Científicas e Tecnológicas do Estado do Amapá (IEPA), GEA, Rod. JK, s/n., Distrito de Fazendinha, 68900280, Macapá, AP, Brasil. E-mail: silvabms@ hotmail.com. Autor para correspondência.

"IIUniversidade Estadual Paulista (UNESP), Jaboticabal, SP, Brasil. 
A redução da luminosidade, da temperatura e da umidade de ambos, sementes e ambiente, fazem com que o metabolismo e a infestação por microrganismos sejam reduzidos, aumentando a longevidade das sementes (VIEIRA et al., 2001). No entanto, quanto maior a temperatura e a umidade no armazenamento, maior será a atividade fisiológica da semente e, por conseguinte, mais rápida a sua deterioração(FLORIANO, 2004).

As sementes ortodoxas podem ser desidratadas até atingir baixos teores de água e, em uma gama de ambientes, sendo que a longevidade no armazenamento aumenta com a diminuição do teor de água delas e da temperatura do ambiente (HONG \& ELLIS, 2003). Dessa forma, as sementes ortodoxas podem ser armazenadas com menos de $10 \%$ de umidade, mantendo ou aumentando a sua longevidade (BONNER, 1989). De acordo com HONG \& ELLIS (2003), as embalagens impermeáveis são adequadas para o armazenamento de sementes ortodoxas por períodos de 2 a 10 anos, em temperaturas de 0 a $10^{\circ} \mathrm{C}$, com teor de água de 8 a 10\%. Dessa forma, no presente trabalho, objetivou-se determinar a embalagem e a temperatura adequadas para o armazenamento de sementes de carolina (Adenanthera pavonina L. Fabaceae).

\section{MATERIAL E MÉTODOS}

As sementes de carolina foram obtidas de frutos maduros colhidos em matrizes localizadas nos logradouros (Praça Veiga Cabral, Praça Beira Rio e Praça Barão do Rio Branco), no Município de Macapá e Amapá - Brasil, antes da dispersão natural e, em seguida, foram colocadas para secar à sombra por 24 horas em temperatura ambiente. Posteriormente, os frutos foram torcidos manualmente para a retirada das sementes e, por fim, as análises e o armazenamento foram realizados no Laboratório de Sementes do Departamento de Produção Vegetal da Faculdade de Ciências Agrárias e Veterinárias, Campus de Jaboticabal.

Para o armazenamento, as sementes foram acondicionadas em sacos de papel e de plástico (polietileno transparente - $0,4 \mathrm{~mm}$ ) e mantidas nas temperaturas de $0 \pm 2 ; 10 \pm 2 ; 20 \pm 2^{\circ} \mathrm{C}$ e $60 \pm 5 \%$ de umidade relativa do ar (UR), assim como na temperatura ambiente de $23,4 \pm 3,3^{\circ} \mathrm{C}$ e $68,7 \pm 9 \%$ de UR por $3,6,9$ e 12 meses.

$\mathrm{O}$ teor de água das sementes foi determinado por meio da secagem de 10 sementes (quebradas com auxílio de alicate), em quatro repetições, em estufa a $105 \pm 3^{\circ} \mathrm{C}$ durante 24 horas (BRASIL, 2009), com modificações no número de sementes e de repetições.
O teste de germinação das sementes foi realizado por meio da semeadura em caixas de plástico $(11 \times 11 \times 3,5 \mathrm{~cm})$, entre areia (SOUZA et al., 2007) umedecida com cerca de $60 \%$ da sua capacidade de retenção em solução aquosa de benlate (Benomyl 500) a $0,1 \%$, mantidas à temperatura de $30^{\circ} \mathrm{C}$ (KISSMANN et al., 2008) e com fotoperíodo de 12 horas. Trimestralmente, a germinação e o vigor das sementes armazenadas foram avaliados conforme metodologia descrita anteriormente e, na última avaliação, no décimo quinto dias após a semeadura, a massa seca das plântulas foi determinada por meio da secagem em estufa a $70 \pm 5^{\circ} \mathrm{C}$ durante 72 horas, conforme $\operatorname{BENINCASA}(2003)$.

Para avaliação diária da germinação das sementes até o décimo quinto dia após a semeadura, o critério adotado foi o de plântulas normais (BRASIL, 2009). Posteriormente, a porcentagem de germinação foi calculada conforme BRASIL (2009) e o índice de velocidade de germinação (IVG) de acordo com a fórmula $\left(I V G=\frac{G_{1}}{N_{1}}+\frac{G_{2}}{N_{2}}+\ldots+\frac{G_{n}}{N_{n}}\right)$ de MAGUIRE (1962), em que $I V G$ =índice velocidade de germinação; $G_{1}, G_{2}$ e $G_{n}$ = número de sementes germinadas na primeira, segunda e última contagem; $\mathrm{N}_{1}, \mathrm{~N}_{2}, \mathrm{~N}_{\mathrm{n}}=$ número de dias decorridos da semeadura na primeira, segunda e última contagem.

Para a porcentagem e índice de velocidade de germinação, o delineamento experimental foi $o$ inteiramente casualizado, em esquema fatorial $2 \times 4 \times 4$ (embalagens, temperaturas e períodos de armazenamento), em oito repetições de 25 sementes. Para os dados da massa seca, o delineamento experimental adotado foi o inteiramente casualizado, em esquema fatorial 2x4 (embalagens e temperaturas de armazenamento), em oito repetições. A comparação entre as médias foi realizada pelo teste de Tukey a 5\% de probabilidade. Tanto para a porcentagem quanto para o índice de velocidade de germinação foram determinadas as equações de regressão, de acordo com PIMENTEL-GOMES(1987).

\section{RESULTADOS E DISCUSSÃO}

Nas sementes de carolina recém colhidas e armazenadas, o teor de água foi de aproximadamente $8,97 \%$, variando entre 8,28 a $9,27 \%$, com porcentagens de germinação de suas sementes iguais ou superiores a $88 \%$ (Tabelas 1 e 2), pois, de acordo com o conceito de HONG \& ELLIS (2003), as sementes de carolina são classificadas como ortodoxas. De forma semelhante, BARBEDO et al. (2002) classificaram as sementes de 
Tabela 1 - Teor de água de sementes de A. pavonina após a secagem (AS) e armazenadas (AR) em duas embalagens e nas temperaturas de 0, 10 e $20^{\circ} \mathrm{C}$ e em temperatura ambiente (TA).

\begin{tabular}{|c|c|c|c|c|c|c|c|c|}
\hline Parâmetros & \multicolumn{8}{|c|}{ Teor de água (\%) } \\
\hline AS & \multicolumn{8}{|c|}{8,9} \\
\hline $\mathrm{CV}(\%)$ & \multicolumn{8}{|c|}{5,04} \\
\hline \multirow{3}{*}{$\mathrm{AR}$} & 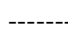 & $---\mathrm{Sa}$ & pel---- & ------ & ----- & $---\mathrm{Sac}$ & tico-- & ------ \\
\hline & $0^{\circ} \mathrm{C}$ & $10^{\circ} \mathrm{C}$ & $20^{\circ} \mathrm{C}$ & TA & $0^{\circ} \mathrm{C}$ & $10^{\circ} \mathrm{C}$ & $20^{\circ} \mathrm{C}$ & TA \\
\hline & 9,2 & 9,1 & 9,0 & 8,2 & 8,9 & 9,0 & 9,1 & 8,9 \\
\hline $\mathrm{CV}(\%)$ & 3,50 & 1,43 & 3,05 & 2,05 & 1,03 & 1,77 & 2,08 & 1,52 \\
\hline
\end{tabular}

pau-brasil (Caesalpinia echinata Lam.) como ortodoxas, pois, mesmo com teores de água próximos de 7,6\% elas germinaram. No entanto, as sementes de ucuuba (Virola surinamensis (Rol.) Warb.) e coca (Erythroxylum ligustrinum DC.) perderam a viabilidade com a redução do teor de água, porque são consideradas recalcitrantes (LIMA et al., 2007; SILVA et al., 2008).

Provavelmente, o tegumento das sementes de carolina, responsável pela dormência, funciona igualmente como mecanismo de proteção durante o armazenamento, pois não houve diferenças para a

Tabela 2 - Porcentagem de germinação de sementes de $\boldsymbol{A}$. pavonina armazenadas em duas embalagens a 0,10 e $20^{\circ} \mathrm{C}$ e na temperatura ambiente (TA).

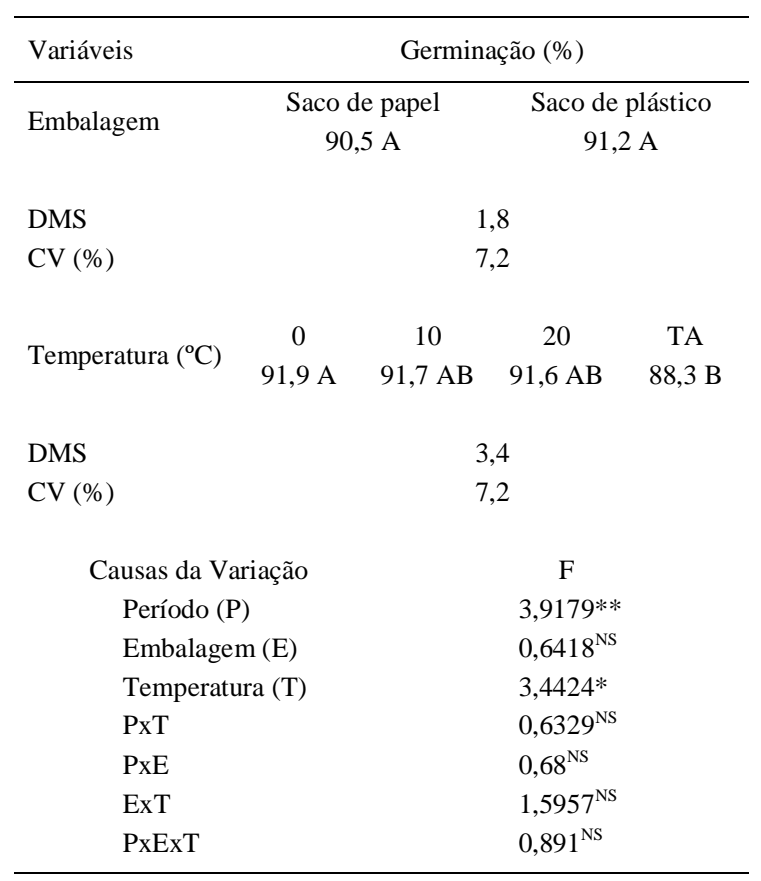

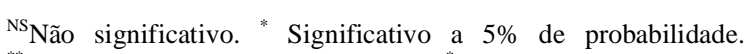
${ }^{* *}$ Significativo a $1 \%$ de probabilidade. "Médias seguidas de letras iguais nas linhas não diferem entre si pelo teste de Tukey a 5\% de probabilidade. porcentagem de germinação de sementes entre as embalagens (Tabela 2). De acordo com PIÑARODRIGUES \& AGUIAR (1993) e FERREIRA \& BORGHETTI (2004), a dormência tegumentar é um mecanismo de proteção para sementes de diversas espécies florestais, principalmente sementes de leguminosas (VASQUEZ-YANES \& OROZCOSEGÓVIA, 1996; FOWLER \& BIANCHETTI, 2000), tanto para a manutenção no banco de sementes do solo quanto para evitar injúrias causadas por patógenos, pragas e animais.

Independentemente das embalagens e períodos de armazenamento, a porcentagem de germinação foi estatisticamente igual nas temperaturas de 0,10 e $20^{\circ} \mathrm{C}$, sendo que na temperatura ambiente a germinação foi estatisticamente igual àquela observada a 10 e $20^{\circ} \mathrm{C}$ e diferente daquela obtida com as sementes armazenadas a $0^{\circ} \mathrm{C}$ (Tabela 2). De acordo com PONTES et al. (2006), as sementes de sibipiruna (Caesalpinia peltophoroides Benth.) armazenadas a $5^{\circ} \mathrm{C}$ mantiveram a porcentagem de germinação constante até 220 dias.

Os dados da porcentagem de germinação das sementes armazenadas a $0{ }^{\circ} \mathrm{C}$ não se ajustaram a modelos de regressão, com média de $92 \%$ durante os 12 meses de armazenamento (Figura 1A), enquanto nas temperaturas de $10 \mathrm{e} 20^{\circ} \mathrm{C}$ e em temperatura ambiente a porcentagem de germinação reduziu linearmente durante os períodos de armazenamento de suas sementes (Figura 1B-D). De acordo com POPINIGIS (1985), o aumento da temperatura provoca a aceleração das atividades respiratórias das sementes e, por conseguinte, a aceleração da deterioração. HARRINGTON (1972) relatou que, para cada $5^{\circ} \mathrm{C}$ de aumento na temperatura de armazenamento, a longevidade da semente é reduzida pela metade.

Os maiores índices de velocidade de germinação foram observados em sementes de carolina armazenadas em sacos de plástico (Tabela 3). De acordo com HONG \& ELLIS (2003), as embalagens impermeáveis são adequadas para o armazenamento de sementes ortodoxas por períodos de 2 a 10 anos, em temperaturas de 0 a $10^{\circ} \mathrm{C}$, com teor de água de 8 a $10 \%$.

Independente das embalagens e períodos de armazenamento, o índice de velocidade de 


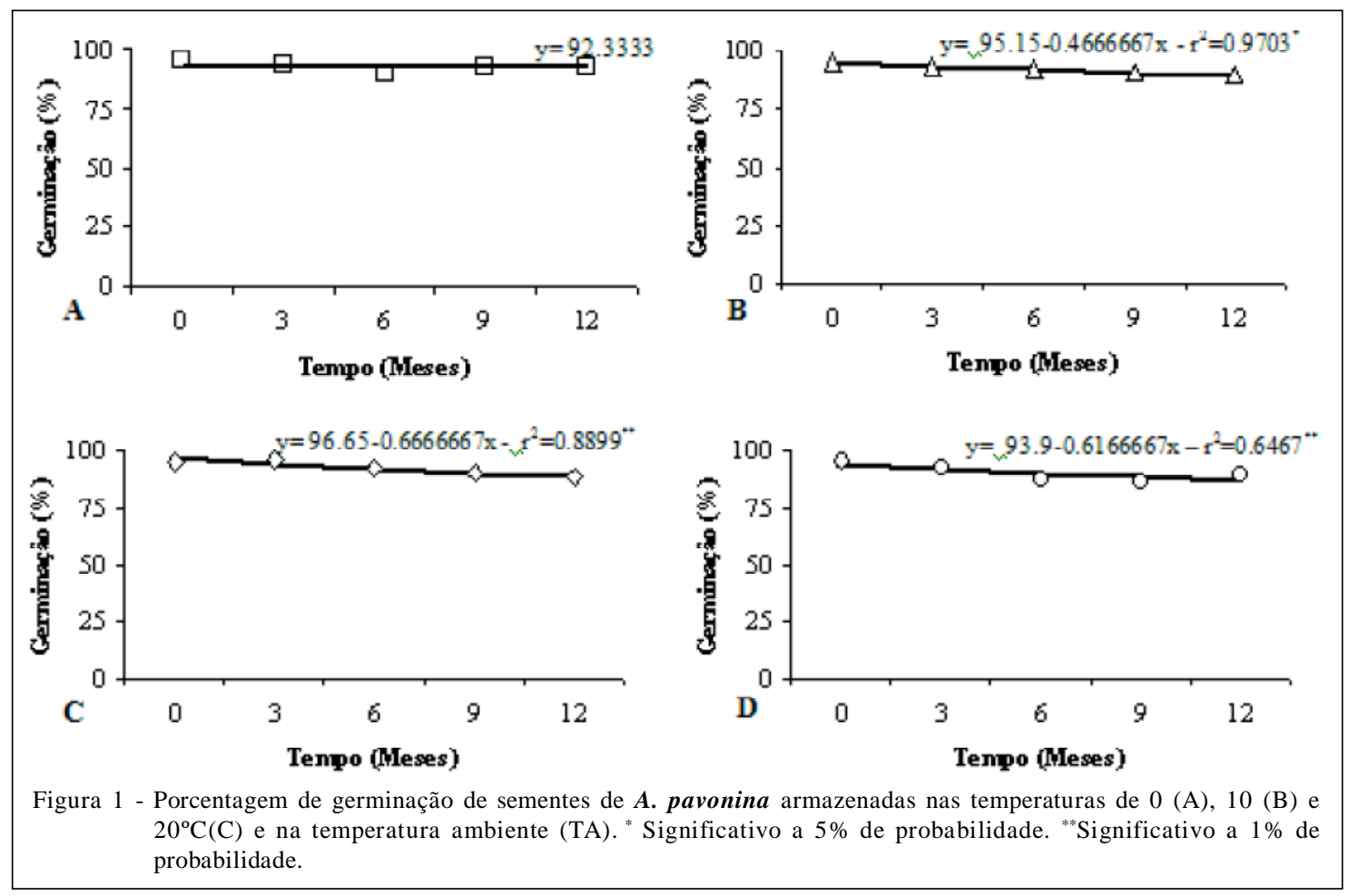

germinação foi estatisticamente igual nas temperaturas 0,10 e $20^{\circ} \mathrm{C}$, sendo que na temperatura ambiente a germinação foi estatisticamente igual a $20^{\circ} \mathrm{C}$ e diferente em comparação com 0 e $10^{\circ} \mathrm{C}$ (Tabela 3 ). De acordo com MARCOS-FILHO (2005), a redução na germinação das sementes é um dos últimos fatores afetados na deterioração, enquanto a velocidade de germinação está diretamente relacionada com o vigor, por conseguinte, um dos primeiros fatores influenciados pela deterioração (CARVALHO \& NAKAGAWA, 2000; MARCOS-FILHO, 2005).

Para os dados do índice de velocidade de germinação de sementes mantidas em sacos de plástico a $10^{\circ} \mathrm{C}$ e em sacos de papel a $0^{\circ} \mathrm{C}$, não houve ajuste a modelos de regressão, com média em torno de 2,29 e 2,37, respectivamente, durante os 12 meses de armazenamento (Figura 2), enquanto as sementes mantidas em 0 e $20^{\circ} \mathrm{C}$ na embalagem de plástico e em $10,20^{\circ} \mathrm{C}$ e na temperatura ambiente em embalagens impermeáveis houve uma tendência linear de redução do índice de velocidade de germinação durante o armazenamento (Figura 2). A redução do índice de velocidade de germinação das sementes armazenadas em temperatura ambiente na embalagem permeável foi mais acentuada, pois diminui quadraticamente em relação ao período de armazenamento de suas sementes (Figura 2). Da mesma forma, o índice de velocidade de germinação foi reduzido em sementes de sibipiruna (Caesalpinia peltophoroides Benth.) armazenadas na
Tabela 3 - Índice de velocidade de germinação de sementes de $\boldsymbol{A}$. pavonina armazenadas em duas embalagens nas temperaturas de 0,10 e $20^{\circ} \mathrm{C}$ e na temperatura ambiente (TA).

\begin{tabular}{|c|c|c|c|c|}
\hline Variáveis & \multicolumn{4}{|c|}{ Índice de velocidade de germinação $\left(\operatorname{dias}^{-1}\right)$} \\
\hline \multirow{2}{*}{ Embalagem } & \multicolumn{2}{|c|}{ Saco de papel } & \multicolumn{2}{|c|}{ Saco de plástico } \\
\hline & \multicolumn{2}{|c|}{$2,211 \mathrm{~B}$} & \multicolumn{2}{|c|}{$2,274 \mathrm{~A}$} \\
\hline DMS & \multicolumn{4}{|c|}{0,0506} \\
\hline $\mathrm{CV}(\%)$ & \multicolumn{4}{|c|}{9,15} \\
\hline \multirow{2}{*}{ Temperatura $\left({ }^{\circ} \mathrm{C}\right)$} & 0 & 10 & 20 & TA \\
\hline & $2,297 \mathrm{~A}$ & $2,286 \mathrm{~A}$ & $2,235 \mathrm{AB}$ & $2,152 \mathrm{~B}$ \\
\hline DMS & \multicolumn{4}{|c|}{0,0940} \\
\hline $\mathrm{CV}(\%)$ & \multicolumn{4}{|c|}{9,15} \\
\hline \multicolumn{2}{|c|}{ Causas da variação } & \multicolumn{3}{|c|}{$\mathrm{F}$} \\
\hline \multicolumn{2}{|c|}{ Período (P) } & \multicolumn{3}{|c|}{$23,5386^{* *}$} \\
\hline \multicolumn{2}{|c|}{ Embalagem (E) } & \multicolumn{3}{|c|}{$6,1534^{*}$} \\
\hline \multicolumn{2}{|c|}{ Temperatura $(\mathrm{T})$} & \multicolumn{3}{|c|}{$6,6452^{* *}$} \\
\hline \multicolumn{2}{|c|}{ PxT } & \multicolumn{3}{|c|}{$0,6702^{\mathrm{NS}}$} \\
\hline PxE & & \multicolumn{3}{|c|}{$1,4177^{\mathrm{NS}}$} \\
\hline ExT & & \multicolumn{3}{|c|}{$0,1867^{\mathrm{NS}}$} \\
\hline PxExT & & \multicolumn{3}{|c|}{$0,7284^{\mathrm{NS}}$} \\
\hline
\end{tabular}

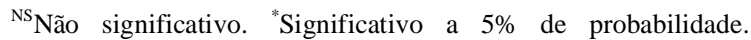
${ }^{* *}$ Significativo a $1 \%$ de probabilidade. *Médias seguidas de letras iguais na linha não diferem entre si pelo teste de Tukey a $1 \%$ de probabilidade.

temperatura de $20^{\circ} \mathrm{C}$ em caixas de papelão (PONTES et al., 2006).

Ciência Rural, v.42, n.1, jan, 2012. 

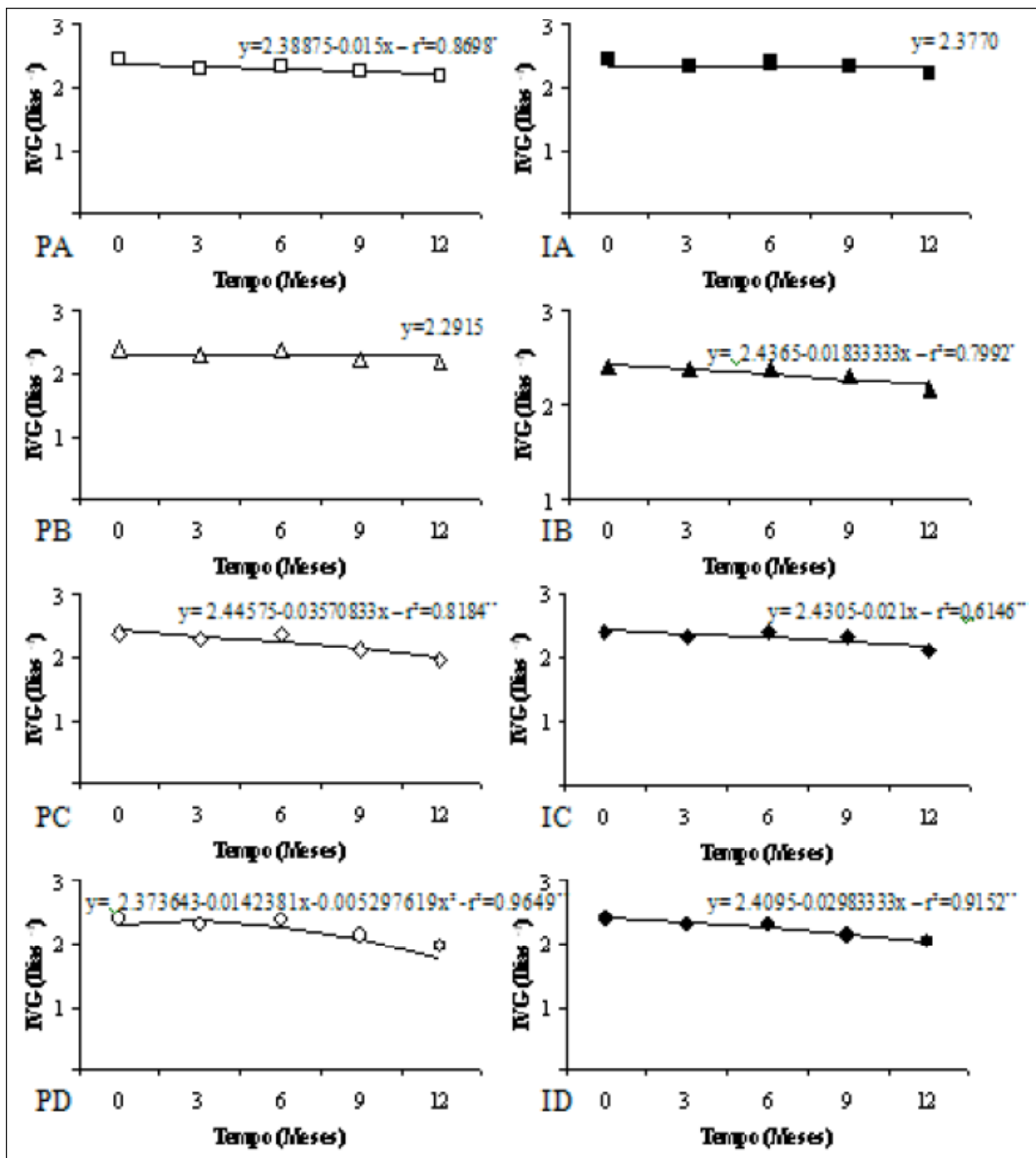

Figura 2 - Índice de velocidade de germinação para sementes de A. pavonina armazenadas em duas embalagens nas temperaturas de 0 (A), 10 (B) e $20^{\circ} \mathrm{C}$ (C) e na temperatura ambiente (TA) (D). P - embalagem permeável (saco de papel). I embalagem impermeável (saco de plástico). ${ }^{*}$ Significativo a $5 \%$ de probabilidade. ${ }^{* *}$ Significativo a $1 \%$ de probabilidade.

Os maiores valores de massa seca foram observados em plântulas originadas de sementes de carolina armazenadas em embalagem impermeável, independente da temperatura. Em relação à temperatura, a massa seca das plântulas foi estatisticamente igual nas temperaturas de 0,10 e $20^{\circ} \mathrm{C}$, sendo que na temperatura ambiente a massa seca foi estatisticamente igual a 10 e $20^{\circ} \mathrm{C}$ e diferente em comparação com $0^{\circ} \mathrm{C}$ (Tabela 4). De acordo com NAKAGAWA (1999), as sementes mais vigorosas produzem potencialmente plântulas mais vigorosas (massa seca). Para faveira (Clitoria fairchildiana R.A. Howard), SILVA \& 
Tabela 4 - Massa seca de plântulas de A. pavonina oriundas de sementes armazenadas em duas embalagens nas temperaturas de 0,10 e $20^{\circ} \mathrm{C}$ e na temperatura ambiente (TA).

\begin{tabular}{|c|c|c|c|c|}
\hline Variáveis & \multicolumn{4}{|c|}{ Massa seca de plântulas (g) } \\
\hline Embalagem & \multicolumn{2}{|c|}{$\begin{array}{c}\text { Saco de papel } \\
0,042 \mathrm{~B}\end{array}$} & \multicolumn{2}{|c|}{$\begin{array}{c}\text { Saco de plástico } \\
0,044 \mathrm{~A}\end{array}$} \\
\hline DMS & \multicolumn{4}{|c|}{0,0016} \\
\hline $\mathrm{CV}(\%)$ & \multicolumn{4}{|c|}{7,24} \\
\hline Temperatura $\left({ }^{\circ} \mathrm{C}\right)$ & $\begin{array}{c}0 \\
0,045 \mathrm{~A}\end{array}$ & $\begin{array}{c}10 \\
0,043 \mathrm{AB}\end{array}$ & $\begin{array}{c}20 \\
0,043 \mathrm{AB}\end{array}$ & $\begin{array}{c}\text { TA } \\
0,041 \mathrm{~B}\end{array}$ \\
\hline DMS & & & 0,0029 & \\
\hline $\mathrm{CV}(\%)$ & & & 7,24 & \\
\hline Causas da Variaçã & & & $\mathrm{F}$ & \\
\hline Embalagem (E) & & & $7,6345^{* *}$ & \\
\hline Temperatura $(\mathrm{T})$ & & & $5,6226^{*}$ & \\
\hline ExT & & & $1,3866^{\mathrm{N}}$ & \\
\hline
\end{tabular}

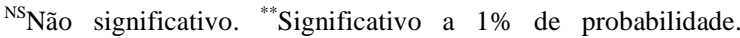
*Médias seguidas de letras iguais na linha não diferem entre si pelo teste de Tukey a $1 \%$ de probabilidade.

CARVALHO (2008) observaram que as sementes mais vigorosas produziram plântulas com maiores acúmulos de massa seca.

\section{CONCLUSÃO}

As embalagens impermeáveis (sacos de plástico) e/ou a temperatura de $0^{\circ} \mathrm{C}$ são mais adequadas para o armazenamento de sementes de carolina.

\section{REFERÊNCIAS}

BARBEDO, C.J. et al. Tolerância à dessecação e armazenamento de sementes de Caesalpinia echinata Lam. (pau-brasil), espécie da mata atlântica. Revista Brasileira de Botânica, v.25, n.4, p.431-439, 2002. Disponível em: <http://www.scielo.br/ pdf/rbb/v25n4/a07v25n4.pdf>. Acesso em: 25/05/2011.

BENINCASA, M.M.P. Análise de crescimento de plantas. 2.ed. Jaboticabal: FUNEP, 2003. 42p.

BONNER, F.T. Seed biology. In: Woody-plant seed manual. (s.1.): USDA Forest Service's/Reforestation, Nurseries, \& Genetics Resources, 2001. 47p. Disponível em: <http://www.nsl.fs.fed.us/ wpsm/>. Acesso em: 25/05/2011.http.

BONNER, F.T. Tropical forest seeds: biology, quality and technology. In: SIMPÓSIO BRASILEIRO SOBRE SEMENTES FLORESTAIS, 2., 1989, Atibaia, SP. Anais... Atibaia, São Paulo: SEMA-SP/IF, 1989. p.263-274.

BRASIL. Ministério da Agricultura, Pecuária e Abastecimento. Regras para análises de sementes. Secretaria de Defesa Agropecuária. Brasília: MAPA/SDA/ACS, 2009. 395p.
CARVALHO, D. et al. Eletroforese de proteínas e isoensimas em sementes de Copaifera langsdorffii Desf. (LeguminosaeCaesalpinioideae) envelhecidas artificialmente. Revista Árvore, v.30, n.1, p.19-24, 2006. Disponível em: <http:// www.scielo.br/pdf/rarv/v30n1/28504.pdf>. Acesso em: 25 maio, 2011.

CARVALHO, N.M.; NAKAGAWA, J. Sementes: ciência, tecnologia e produção. 4.ed. Jaboticabal: FUNEP, 2000. 588p.

FERREIRA, A.G.; BORGHETTI, F. (Eds.). Germinação: do básico ao aplicado. Porto Alegre: Artmed, 2004. 323p.

FLORIANO, E.P. Armazenamento de sementes florestais. Santa Rosa - RS: ANORGS, 10p. In: UFSM. Armazenamento de sementes, 2004. Disponível em: <http:// www.ufsm.br/sementes>. Acesso em: 25 maio, 2011.

FOWLER, A.J.P.; BIANCHETTI, A. Dormência em sementes florestais. Colombo: EMBRAPA Florestas, 2000. 27p. (EMBRAPA Florestas. Documentos, 40). Disponível em: <http://ainfo.cnptia.embrapa.br/digital/bitstream/item/ 16837/1/doc40.pdf>. Acesso em: 25 maio, 2011.

HARRINGTON, J.N. Seed storage and longevity. In: KOZLOWSKI, T.T. (Ed.). Seed biology. New York: Academic, 1972. V.3, p.145-245.

HONG, T.D.; ELLIS, R.H. Storage. In: Tropical tree seed manual. [s.1]: USDA Forest Service's, Reforestation, Nurseries \& Genetics Resources, 2003. p.125-136.

KISSMANN, C. et al. Tratamentos para quebra de dormência, temperaturas e substratos na germinação de Adenanthera pavonina L. Ciência e Agrotecnologia, v.32, n.2, p.668674, 2008. Disponível em: <http://www.scielo.br/pdf/cagro/ v32n2/51.pdf>. Acesso em: 25 maio, 2011.

LIMA, J.D. et al. Germinação e armazenamento de sementes de Virola surinamensis Warb. (Myristicaceae). Revista Árvore, v.31, n.1, p.37-42, 2007. Disponível em: <http://www.scielo.br/ pdf/rarv/v31n1/05.pdf>. Acesso em: 25 maio, 2011.

LORENZI, H. et al. Árvores exóticas no Brasil: madeireiras, ornamentais e aromáticas. Nova Odessa: Instituto Plantarum, 2003. 173p.

MAGUIRE, J.A. Speed of germination aid in selection an evaluation for seedling emergence and vigor. Crop Science, v.2, n.2, p.176-177, 1962. Disponível em: <https:// www.soils.org/publications/cs/abstracts/2/2/CS0020020176>. Acesso em: 25 maio, 2011.

MARCOS-FILHO, J. Fisiologia de sementes de plantas cultivadas. Piracicaba: FEALQ, 2005. 495p.

NAKAGAWA, J. Testes de vigor baseados no desempenho das plântulas. In: KRZYZANOWSKI, F.C. et al. Vigor de sementes: conceitos e testes. Londrina: ABRATES, 1999. p. $2-15$.

NODARI, R.O. et al. Conservação de frutos e sementes de palmiteiro (Euterpe edulis Mart.) sob diferentes condições de armazenamento. Revista Árvore, v. 22, n.1, p.1-10, 1998. 
PIÑA-RODRIGUES, F.C.M.; AGUIAR, I.B. Maturação de sementes. In: AGUIAR, I.B. et al. Sementes florestais tropicais. Brasília: ABRATES, 1993. p.215-274.

PIMENTEL-GOMES, F. Curso de estatística experimental. São Paulo: Nobel, 1987. 467p.

PONTES, C.A. et al. Influência da temperatura de armazenamento da qualidade das sementes de Caesalpinia peltophoroides Benth. (sibipiruna). Revista Árvore, v.30, n.1, p.43-48, 2006. Disponível em: http://www.scielo.br/pdf/ $\% 0 \mathrm{D} / \mathrm{rarv} / \mathrm{v} 30 \mathrm{n} 1 / 28507$.pdf. Acesso em: 25 maio, 2011.

POPINIGIS, F. Fisiologia da semente. Brasília: Agiplan, 1985. 289p.

ROCAS, A.N. Adenanthera pavonina L. In: VOZZO, J.A. (Org.). Tropical tree seed manual. United States: Department of Agriculture Forest Service, 2003. p.269-271.

SILVA, B.M.S.; CARVALHO, N.M. Efeitos do estresse hídrico sobre o desempenho germinativo da semente de faveira (Clitoria fairchildiana R. A. Howard. - Fabaceae) de diferentes tamanhos. Revista Brasileira de Sementes, v.30, n.1, p.55-65, 2008. Disponível em: <http://www.scielo.br/pdf/rbs/v30n1/ a08v30n1.pdf $>$. Acesso em: 25 maio, 2011.
SILVA, B.M.S. et al. Germinação e armazenamento de sementes de coca (Erythroxylum ligustrinum DC. - Erythroxylaceae). Revista Brasileira de Sementes, v.30, n.3, p.25-29, 2008. Disponível em: 〈http://www.scielo.br/pdf/rbs/v30n3/04.pdf>. Acesso em: 25 maio, 2011.

SOUZA, E.B. et al. Germinação de sementes de Adenanthera pavonina $\mathrm{L}$. em função de diferentes temperaturas e substratos. Revista Árvore, v.31, n.3, p.437-443, 2007. Disponível em: <http://www.scielo.br/pdf/rarv/v31n3/09.pdf>. Acesso em: 25 maio, 2011.

VASQUEZ-YANEZ, C.; OROZCO-SEGOVIA, A. Comparative longevity of seeds of five tropical rain forest woody species stored under different moisture conditions. Canadian Journal of Botany, v.74, n.10, p.1635-1639, 1996. Disponível em: <http://www.nrcresearchpress.com/doi/abs/10.1139/b96-198>. Acesso em: 25 maio, 2011. doi: 10.1139/b96-198.

VIEIRA, A.H. et al. Técnicas de produção de sementes florestais. Porto Velho: EMBRAPA, CT 205, 2001. p.1-4. Disponível em: <http://www.infoteca.cnptia.embrapa.br/ bitstream/doc/863141/1/Cot205.pdf $>$. Acesso em: 25 maio, 2011. 